\title{
Erratum to: Hemorrhagic synovial cyst as an 'evanescing' spinal cervical mass: an issue for differential diagnosis
}

Giulio Conforti - Giuseppe Maria Della Pepa •

Fabio Papacci - Alba Scerrati - Nicola Montano

Published online: 21 February 2014

(c) Belgian Neurological Society 2014

\section{Erratum to: Acta Neurol Belg}

DOI 10.1007/s13760-013-0277-4

In the published original article, the family name of two authors are not given correct. The correct names are:

G. M. Della Pepa (not G. M. D. Pepa).

A. Scerrati (not S. Alba).

The online version of the original article can be found under doi:10.1007/s13760-013-0277-4.

G. Conforti ( $₫)$ · G. M. Della Pepa · F. Papacci · A. Scerrati · N. Montano Institute of Neurosurgery, Catholic University,

L-go A.Gemelli, 00168 Rome, Italy

e-mail: confortigiulio@gmail.com 